\title{
Effects of Weekly Module Based Learning in Pathology - A Questionnaire Based Study
}

\author{
M. Rithanya ${ }^{1}$ and M.P.Brundha ${ }^{2 *}$ \\ ${ }^{1}$ Graduate student Saveetha Dental College, Saveetha Institute of Medical \\ and Technical Sciences Saveetha University Chennai-77, India \\ ${ }^{2}$ Associate professor Department of Pathology Saveetha Dental College, \\ Saveetha Institute of Medical and Technical Sciences Saveetha University. \\ Chennai-77, India
}

\section{ABSTRACT}

Module is a unit of work in a course of guidance that is for all intents and purposes independent. It is a strategy for instructing that depends on building up abilities and knowledge in discrete units. The aim of this survey is to find the effects of weekly module based learning in pathology. A questionnaire containing fifteen questions were circulated among 90 students, out of which 75 students of Saveetha dental college, studying second year attended the survey. The results were collected and analysed statistically using SPSS software. The significance, advantages and disadvantages of the weekly module based learning system as said by the respondents were noted. $66.7 \%$ of the participants prefered weekly module based learning in pathology over the conventional learning methods. 53.3\% of the respondents find weekly module based learning system as a better method of studying. A comparison between the student's opinion on better learning methods and if it allows easier follow up to the subjects before the exam and if it provides better correlation between subjects was made through Chi square analysis. There was a significant difference as p-value was 0.000 in both. From this survey, it is evident that the students prefer the weekly module based learning over other conventional methods of learning.

KEY WORDS: WEEKLY MODULE BASED LEARNING, PATHOLOGY.

\section{INTRODUCTION}

Learning is the way toward gaining new, or altering existing, information, practices, aptitudes, qualities, or inclinations (Gross, 2015). Some learning is prompt, stirred by a solitary occasion (for example being scorched by a hot stove), however much aptitude and information gathers from recurrent encounters. The progressions

\section{ARTICLE INFORMATION}

${ }^{*}$ Corresponding Author: brundha.sdc@saveetha.com Received 29th July 2020 Accepted after revision 28th Sep 2020 Print ISSN: 0974-6455 Online ISSN: 2321-4007 CODEN: BBRCBA

Thomson Reuters ISI Web of Science Clarivate Analytics USA and Crossref Indexed Journal

\section{Clarivate ${ }_{\text {Analytics }}$ rossef}

NAAS Journal Score 2020 (4.31) SJIF: 2020 (7.728)

A Society of Science and Nature Publication,

Bhopal India 2020. All rights reserved.

Online Contents Available at: http//www.bbrc.in/

Doi: http://dx.doi.org/10.21786/bbrc/13.8/138 initiated by learning regularly endure forever, and it is difficult to recognise learned material that is by all accounts "lost" from that which can't be recovered (Hood et al., 2015). Learning may happen intentionally or without consciously being aware. The capacity to learn is present in people, animals and a few machines; there is likewise proof for some sort of learning in specific plants (Kingsland, 2018).

Active learning happens when an individual assumes responsibility for his/her learning experience. Since understanding data is the key part of learning, it is significant for students to perceive what they comprehend and what they don't. Thus, they can screen their very own mastery of subjects. Dynamic learning urges students to have an inside exchange in which they verbalize understandings (Bransford et al., 2006). Active learning draws in learners in two angles - getting things done




and considering the things they are doing (Renkl et al., 2002).

The methodologies for instructing can be extensively characterised into educator focused and students focused. In an instructor focused way to deal with learning, educators are the primary position figure in this model. Students are seen as "unfilled vessels" whose essential job is to inactively get data (by means of talks and direct guidance) with the ultimate objective of testing and evaluation. In this method, instructing and evaluation are seen as two separate parameters . Students' learning is estimated through intently scored tests and evaluations.

In Student-Centered Approach to Learning, while educators are the power figure in this model, instructors and students assume a similarly dynamic job in the learning procedure. The instructor's essential job is to mentor and encourage students learning and generally understanding of material. Students learning is estimated through both formal and casual types of appraisal, including bunch ventures, understudy portfolios, and class investment. Educating and investigation associated; understudy learning is endlessly estimated during instructor guidance (Deng and Yu, 2014).

Module goals help us to thoroughly consider and certainly depict what is needed for students to learn in every module. Similarly as with any plan venture, it is significant, when planning a course, to begin with a reasonable thought of the course's objectives and the results you need to accomplish. Module-based ideas are helpful to learners since they can fill in as a sort of agenda that explains what they should know and have the option to do in the wake of finishing each piece of the course. These targets are likewise helpful from a curricular and methodical point of view (and for program evaluation) since they outline explicitly how the course will meet the methodical learning objectives it is proposed to attain (Anderson, Krathwohl and Bloom, 2001).

Module is a unit of work in a course of guidance that is for all intents and purposes independent and a strategy for instructing that depends on the building up abilities and knowledge in discrete units. "Module is a short unit of instruction dealing with a conception unit of subject matter" - Russel (1974) (Aqazade, 2009). Modular approach is an independent way of managing one explicit subject in a helpful structure, with the goal that the student can finish it at his or her own pace freely or in little groups. It is organized to such an extent that the student can recognize the goal, select material and technique and assess his very own achievement (Adibnia, 2010).

The essential components of module based learning are rationale - a sketch of the outline of the module and clarification of why the students should learn it, objectives - expressed in performance terms about the outcome of the module, Entry test - to determine if the learner has the required skills to start the module and to find how much knowledge he/ she has about the subject that is going to be taught, Multimedia materials - a wide range of media like pictures and videos are used to actively involve the learner's senses, Learning activities like presentations, drills, demonstrations, problems solving and simulation are useful in increasing the interest of the students and caters the student's needs. Self test is also one of the requirements as it provides a chance to check one's own progress. Another requirement is a post test which is basically an examination to check if the goal of the module has been reached (Joyce, Kalhun and Hapkins, 2009).

Advantages of module based learning are that studying becomes more effective and impactful. Instead of normal marks and grades, it provides a system of evaluation. Learner's can study without interference from normal works and responsibilities. Modules can be taught for either once use, small or big groups. Modules are adaptable with the goal that execution can be made by an assortment of patterns. It's more relevant to mature learners and enables the learners to have an authority or command over his learning.

Disadvantages include that module based learning requires smart classrooms, and that modules are economical in their use. Moreover this type of learning is appropriate mainly for mature students (Oberhuemer and Ulich, 1997). To sum it up, module based learning is more efficient, latest and more technology based learning method in the current educational field.

\section{MATERIAL AND METHODS}

This is a questionnaire based survey in which a set of fifteen questions were distributed through an online survey platform called Surveyplanet. The survey was attended by second year students of Saveetha dental college. The questionnaire contained questions enquiring about the advantages and disadvantages of weekly module based learning and preferences of the students on the methodologies of learning. The questionnaire was distributed online to about 90 students wherein 75 students attended the survey. The ratings of weekly module based learning by the participants is also recorded. Results were obtained and analysed using proper statistical methods with the help of SPSS software and thus the preference of learning methods and the opinions on weekly module based learning of the students is studied. Chi square test was used and Pearson correlation analysis was used to assess the correlation between the variables. The results were considered to be of statistical significance if $\mathrm{p}<0.05$.

\section{RESULT AND DISCUSSION}

As the weekly module based learning system is solely focused on completing the entire portion in a week, the students were asked how they felt about completion of the portions in a week. $46.7 \%$ felt it to be manageable, $34.7 \%$ of the students felt that completing the whole portion in a week felt hectic while the remaining 18.7\% 
of the students felt completion of the whole portion of the subject in a week as an easy task (Figure 1). Then the students were asked if they felt weekly module based learning is better than the conventional method of learning. 66.7\% responded yes and 33.3\% responded no (Figure 2). An article by EZF Liu, CH Lin et al., shows similar results claiming weekly module based learning to be better than the conventional method of learning among Taiwanese students (Liu and Lin, 2010).

Figure 1: Pie Chart showing students' view on completion of the whole portion in a week. $18.67 \%$ respondents feel completion of whole portions in a week is easy (blue), 46.67\% manageable (red) and 34.67\% hectic (green).

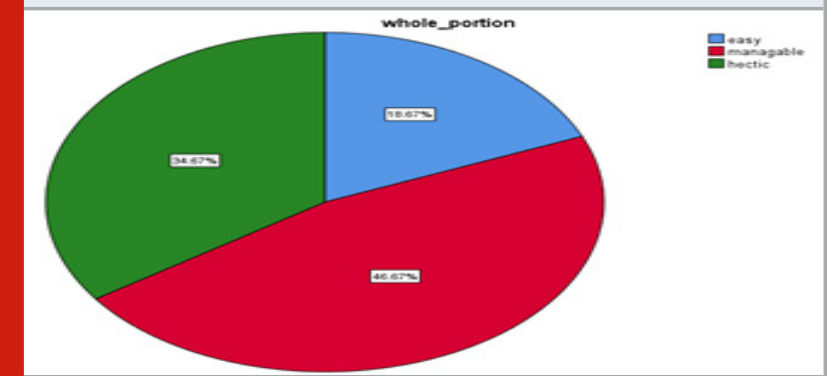

Figure 2 : Pie Chart showing students' opinion on better methods of studying. $66.67 \%$ of the respondents said that module based learning is better than the conventional method of learning (blue) and 33.33\% said conventional method is better (red).



Figure 3: Pie Chart showing students' opinion on if module based learning allows more clarity. 53.33\% respondents reported it allows more clarity (blue) and $46.67 \%$ does not (red).

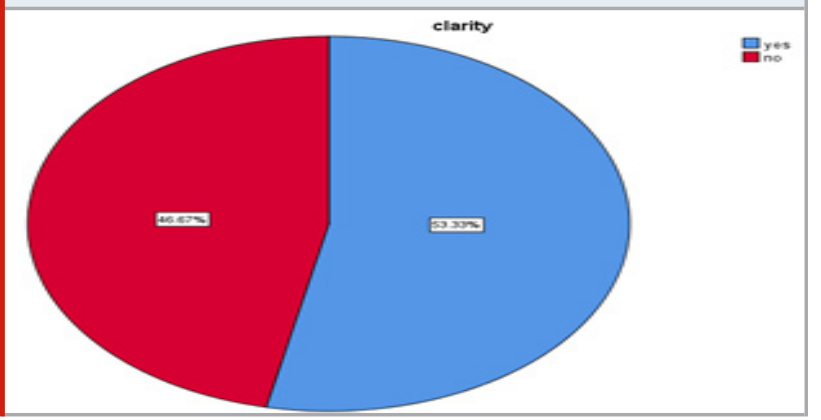

Then the participants were asked if this weekly module based system provides much more clarity than the conventional system of learning. 53.3\% of the participants find weekly module based learning to be more clearer and precise with clarity. $46.7 \%$ of them find conventional learning methods to provide more clarity (Figure 3). A study by Z Kallar, et al., supports this concept as it is stated that module based learning provides a better clarity and insight into the subject (Kalmár, Szepesvári and Larincz, 1998). 65.3\% of the participants find that weekly module based learning grants more time to concentrate on a particular subject than in conventional method while the minority of $34.7 \%$ felt otherwise (Figure 4).

Figure 4: Pie Chart showing students' opinion on if module based systems allows more time to concentrate on a particular subject. $65.33 \%$ of the respondents felt it allows more time to concentrate (blue) and $34.67 \%$ did not (red).

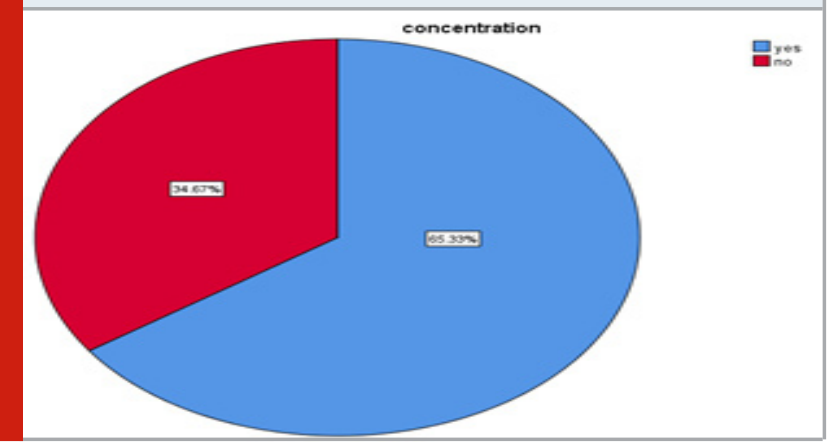

Figure 5: Pie Chart showing students' opinion on studying the same subject all day. $46.67 \%$ respondents felt comfortable (blue) and 53.33\% students were unable to concentrate well (red).

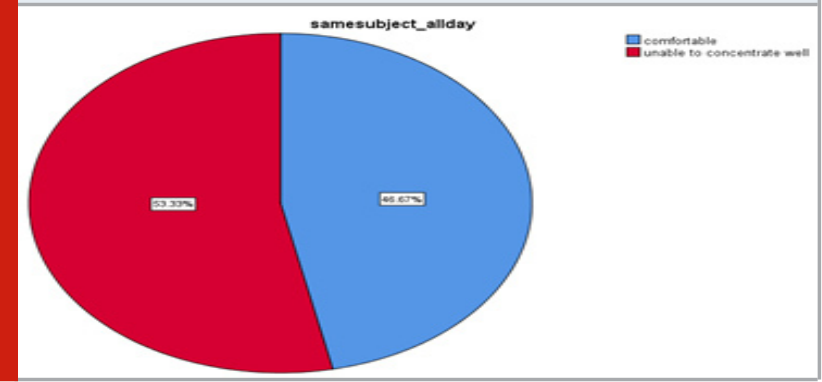

The students were then asked their opinion on studying the same subject all day. It was found that 55.3\% of the students were unable to concentrate on the same subject for an extended period of time while $46.7 \%$ of the survey attendees were comfortable with studying the subject for a long duration (Figure 5). A predominant of 66.7\% students believe weekly module based learning provides easier correlation to the subject. 33.3\% of the students however do not share the opinion ( Figure 6). It is stated in an article by SY Hwang that module based study setting allows a good correlation between subjects, when done in the right order (Hwang and Chang, 2000).

The weekly module based learning enables students to complete the portions in a short period of time which eventually allows more revisions and recollections. The 
next question directed towards the students was based on this. They were asked if they could follow up easily with the subject. A majority of the participants, that is 53.3\% found that module based learning method allows easier follow up while 46.7\% thought otherwise (Figure 7). 57.3\% of the participants felt that they would be able to study the whole portion if the subject is completely finished. $42.7 \%$ of the participants however do not think they would be able to study the whole portion if the subject is completely finished (Figure 8).

Figure 6: Pie Chart showing students' opinion on if it allows easier correlation between subjects. $66.67 \%$ students responded yes (blue) and 33.33\% responded no (red).

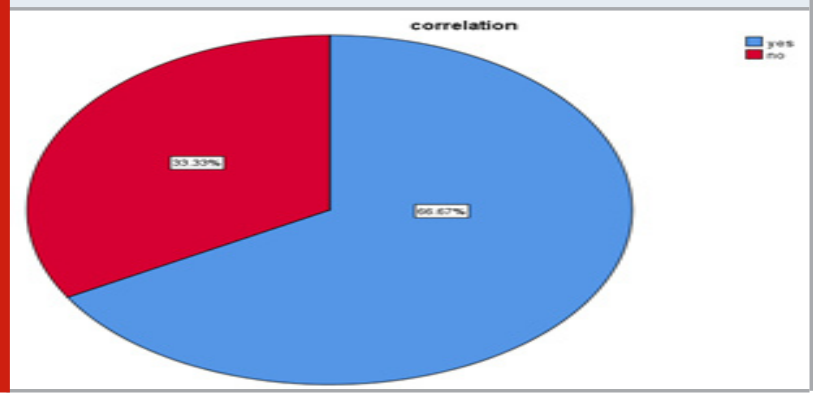

Figure 7 : Pie Chart showing students' view on if it allows easier follow up. 53.33\% respondents feel it allows easier follow up (blue) and 46.67\% felt it does not allow easier follow up (red).

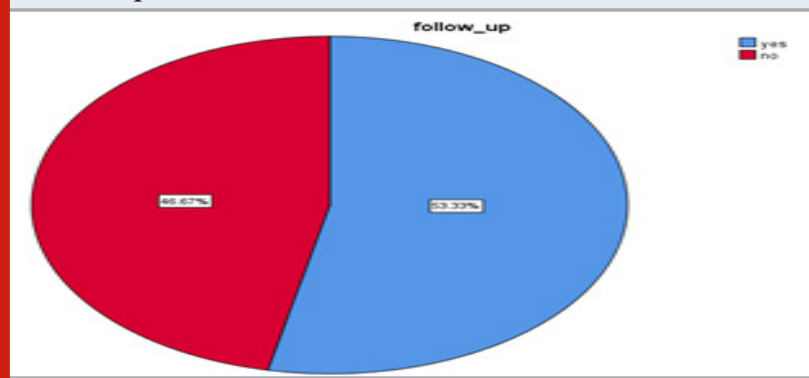

Figure 8 : Pie Chart showing students' possibility to study the whole portion before the exam. 57.33\% felt they could (blue) and 42.76\% felt they couldn't (red).

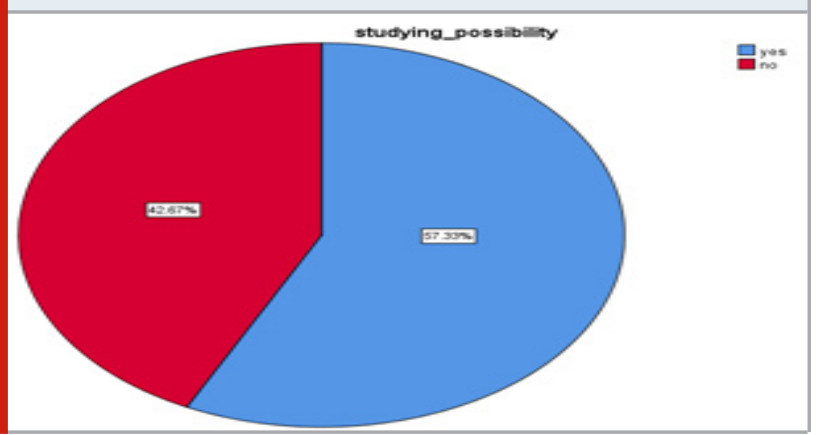

Nowadays, there are a variety of options in the method of learning. In various places, different methods of teaching techniques are used. Some among them are adult learning, interactive lectures and symposium. It was seen in the survey that $17.3 \%$ preferred adult learning methods, 68\% were fond of interactive lectures and 14.7\% preferred symposium type of learning (Figure 9). When asked to choose between panel discussion, module based learning and integrated learning, it was found that 34.7\% preferred panel discussion learning, 30.7\% preferred module based learning and 34.7\% seemed to prefer integrated learning (Figure 10). In contrast to this, integrated learning was the most preferred learning method in the survey conducted by Dowson $\mathrm{M}$ and McInerney DM (Dowson and McInerney, 2004).

Figure 9: Pie Chart showing students' preferred methods of learning. 17.33\% prefer adult learning (blue), 68\% prefer interactive lectures (red) $14.67 \%$ prefer symposium (green).

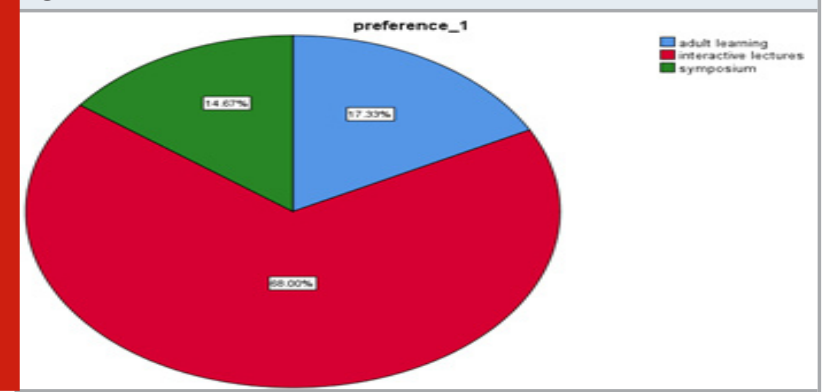

Figure 10: Pie Chart showing students' other preferred methods of learning. $34.67 \%$ students prefer panel discussion (blue), 30.67\% prefer module based learning (red) and 34.67\% prefer integrated learning (green).

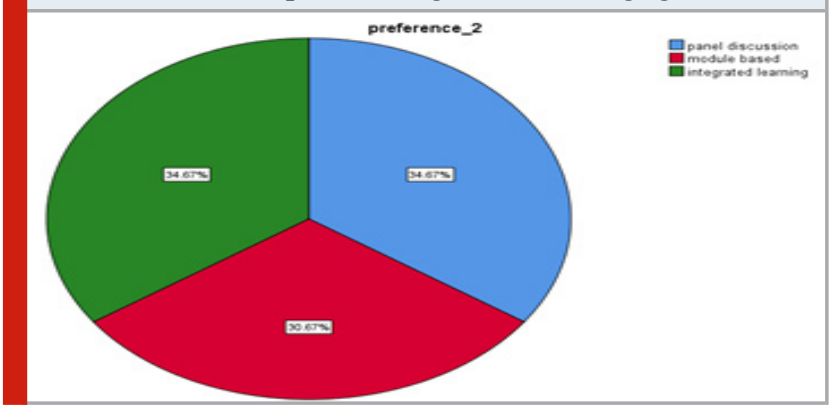

Figure 11: Pie Chart showing students' aAwareness on MILA technique. 70.67\% are aware (blue) and 29.33\% are not aware (red).

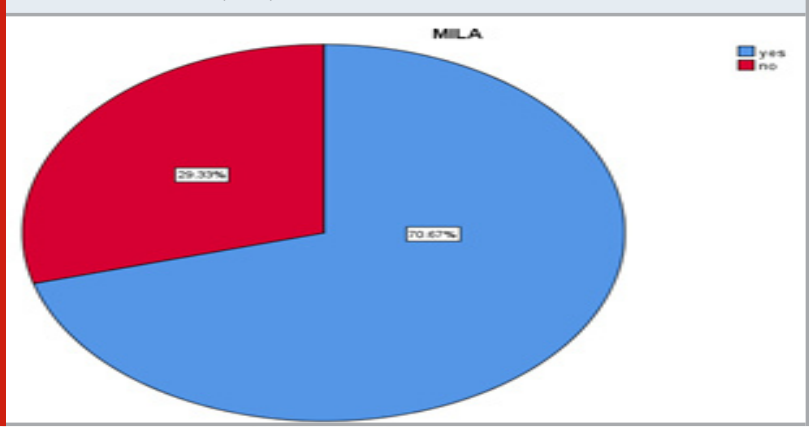

MILA is one of the best learning methods. MILA stands for Multiple Interactive Learning Algorithm in which six segments are present with two hour lectures. $71.8 \%$ of the 
participants were aware about this system while $28.2 \%$ were not aware (Figure 11). Module based learning has many advantages. When asked about it, 38.7\% found that this system allows more clarity on the subject, 33.3\% felt completion of the whole subject in a week as a boon and 28\% felt the most advantageous factor in this system is that it allows to concentrate on one subject at a time (Figure 12).

Figure 12: Pie Chart showing students' view on advantages in module based technique. $38.67 \%$ chose it allows more clarity (blue), 33.33\% chose completion of whole portions in a week (red) and $28 \%$ chose it allows more time to concentrate (green).

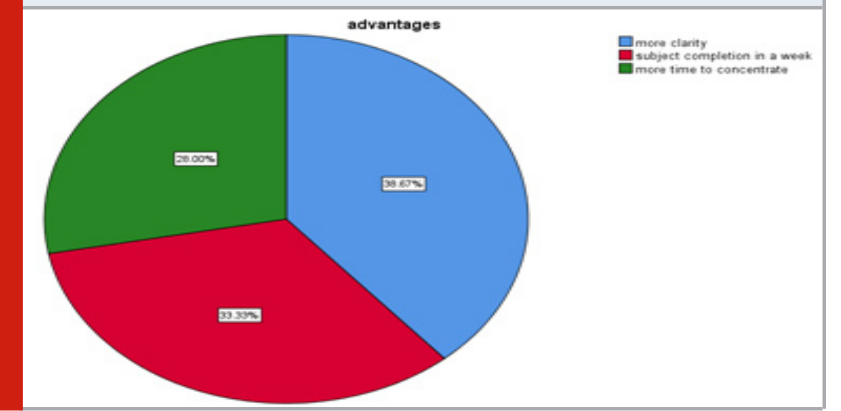

A comparison between the student's opinion on better learning methods and if it allows easier follow up to the subjects before the exam was made through Chi square analysis (Figure 13). There was a significant difference as p-value was 0.000 . The Chi square analysis for comparison between better learning methods and if it allows easier correlation between subjects was made (Figure 14). There was a significant difference as p-value was 0.000 .

Figure 13: The bar graph represents the comparison of responses by students of Pathology on if the module based system allows easier follow up of the portions before exam. $\mathrm{X}$ axis represents the better learning system and $\mathrm{Y}$ axis represents percentage of participants' response to easier follow up. This graph shows that respondents who chose module based systems are better, predominantly said it allows easier follow up. This is statistically significant. Chi square test, $\mathrm{p}$-value $=0.000(<0.05)$, hence statistically significant.

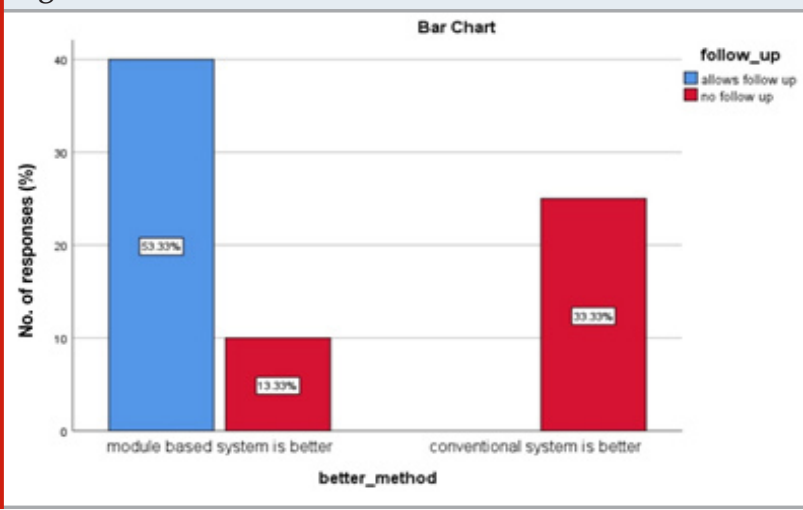

As said in the article "The Impact of Active and ContextBased Learning in Introductory Chemistry Courses: An Early Evaluation of the Modular Approach" by Joshua P. Gutwill that the students in the modular learning system outperformed the control group on conceptual problems in chemistry, similarly the students of General Pathology also showed positive outcomes on weekly module based learning in the survey they attended as they found weekly module based learning to be beneficial. It is also established that weekly module based learning provides more clarity and time to concentrate on a particular subject (Gutwill-Wise, 2001).

Figure 14: The bar graph represents the comparison of responses by students of Pathology on if the module based system allows easier correlation between subjects. $\mathrm{X}$ axis represents the better learning system and $\mathrm{Y}$ axis represents percentage of participants' response to easier correlation. This graph shows that all respondents who chose module based systems are better, said it allows better correlation between subjects. This is statistically significant. Chi square test, p-value $=0.000(<0.05)$, hence statistically significant.



The paper by Prince MJ, Felder RM characterises every strategy, features shared commonalities and explicit contrasts, and audits inquiry about the adequacy of the techniques. While the quality of the proof shifts starting with one technique then onto the next, inductive strategies are reliably seen as at least equivalent to, and done more effectively than, conventional deductive techniques for accomplishing a wide scope of learning results (Prince and Felder, 2006).

\section{CONCLUSION}

From this survey, it is evident that the students prefer the weekly module based learning over other conventional methods of learning as it helps them better to understand and remember the concepts, allows easier recollection of the subject and provides more time to concentrate on the same subject. It also provides a long duration to concentrate on a particular subject along with accommodating easier correlation between the subjects. 


\section{ACKNOWLEDGEMENTS}

M.Rithanya contributed to the execution of the work, data collection and drafting of the manuscript. Dr.M.P.Brundha contributed to the concept, design of the study, validation of the data collection, revision and proofreading of the article.

Conflict of Interest: None to declare

\section{REFERENCES}

Adibnia, A. (2010) 'Teaching methods of natural science', Isfahan: Kankash publication.

Anderson, L. W., Krathwohl, D. R. and Bloom, B. S. (2001)

A taxonomy for learning, teaching, and assessing: a revision of Bloom's taxonomy of educational objectives. Longman.

Aqazade, M. (2009) 'Guidance to new teaching methods', Tehran: Ayij publication.

Bransford, J. D. et al. (2006) 'Foundations and Opportunities for an Interdisciplinary Science of Learning', in Sawyer, R. K. (ed.) The Cambridge handbook of: The learning sciences , (pp. New York, NY, US: Cambridge University Press, xix, pp. 19-34. Deng, L. and Yu, D. (2014) 'Deep Learning: Methods and Applications', Found. Trends Signal Process. Hanover, MA, USA: Now Publishers Inc., 7(3-4), pp. 197-387.

Dowson, M. and McInerney, D. M. (2004) 'The Development and Validation of the Goal Orientation and Learning Strategies Survey (Goals-S)', Educational and psychological measurement. SAGE Publications Inc, 64(2), pp. 290-310.

Gross, R. (2015) Psychology: The Science of Mind and Behaviour 7th Edition. Hachette UK.

Gutwill-Wise, J. P. (2001) 'The Impact of Active and Context-Based Learning in Introductory Chemistry Courses: An Early Evaluation of the Modular Approach', Journal of chemical education. American Chemical Society, 78(5), p. 684.

Hood, B. M. et al. (2015) Psychology: Second European Edition. Macmillan Education UK.
Hwang, S.-Y. and Chang, K.-S. (2000) 'The Development and Implementation of Problem-Based Learning Module Based on Lung Cancer Case', The Journal of Korean Academic Society of Nursing Education. The Korean Academic Society of Nursing Education, 6(2), pp. 390-405.

Joyce, B., Kalhun, E. and Hapkins, D. (2009) 'Learning models of teaching instruments (Translated by: Mahmood Mehrmohammadi and Lotfali Abedi)', Tehran: SAMT. (Publication data in original language 1949).

Kalmár, Z., Szepesvári, C. and L囚rincz, A. (1998) 'Module-Based Reinforcement Learning: Experiments with a Real Robot', Autonomous robots, 5(3), pp. 273-295.

Kingsland, S. (2018) 'Courtney Fullilove. The Profit of the Earth: The Global Seeds of American Agriculture. 280 pp., figs., index. Chicago/London: University of Chicago Press, 2017. 40 (cloth).Helen Anne Curry. Evolution Made to Order: Plant Breeding and Technological Innovation in Twentieth-Century America. x 285 pp., figs., bibl., index. Chicago/London: University of Chicago Press, 2016. 45 (cloth)', Isis, pp. 406-409. doi: 10.1086/697914.

Liu, E. Z. F. and Lin, C. H. (2010) 'The survey study of mathematics motivated strategies for learning questionnaire (MMSLQ) for grade 10-12 Taiwanese students', TOJET: The Turkish Online Journal of Educational Technology, 9(2). Available at: http://www. tojet.net/articles/v9i2/9223.pdf.

Oberhuemer, P. and Ulich, M. (1997) Working with Young Children in Europe: Provision and Staff Training. SAGE.

Prince, M. J. and Felder, R. M. (2006) 'Inductive Teaching and Learning Methods: Definitions, Comparisons, and Research Bases', Journal of Engineering Education, pp. 123-138. doi: 10.1002/j.2168-9830.2006.tb00884.x.

Renkl, A. et al. (2002) 'From Example Study to Problem Solving: Smooth Transitions Help Learning,, Journal of experimental education. Routledge, 70(4), pp. 293-315. 